This item was submitted to Loughborough's Research Repository by the author.

Items in Figshare are protected by copyright, with all rights reserved, unless otherwise indicated.

\title{
Correlation of ISO 16840-2:2007 impact damping and hysteresis measures for a sample of wheelchair seating cushions
}

\section{PLEASE CITE THE PUBLISHED VERSION}

http://dx.doi.org/10.1080/10400435.2016.1261963

\section{PUBLISHER}

(C) RESNA. Published byTaylor \& Francis

\section{VERSION}

AM (Accepted Manuscript)

\section{PUBLISHER STATEMENT}

This work is made available according to the conditions of the Creative Commons Attribution-NonCommercialNoDerivatives 4.0 International (CC BY-NC-ND 4.0) licence. Full details of this licence are available at: https://creativecommons.org/licenses/by-nc-nd/4.0/

\section{LICENCE}

CC BY-NC-ND 4.0

\section{REPOSITORY RECORD}

Hillman, Susan J., James Hollington, Neil Crossan, and Carmen Torres. 2019. "Correlation of ISO 168402:2007 Impact Damping and Hysteresis Measures for a Sample of Wheelchair Seating Cushions". figshare. https://hdl.handle.net/2134/23382. 
Title: Correlation of ISO 16840-2:2007 impact damping and hysteresis measures for a sample of wheelchair seating cushions ${ }^{1 *}$

\section{Authors}

Susan J Hillman², MSc

Rehabilitation Engineering and Aids for Living Unit, Newcastle upon Tyne Hospitals NHS Foundation Trust, Newcastle upon Tyne, UK

James Hollington, MSc

South-east Mobility and Rehabilitation Technology Centre, Edinburgh, Scotland Neil Crossan, BEng

School of Engineering and Physical Sciences, Department of Mechanical Engineering, Heriot-Watt University, Edinburgh, Scotland

Carmen Torres-Sánchez, MEng, PhD

Wolfson School of Mechanical and Manufacturing Engineering, Loughborough University, Leicestershire, England

\section{Abstract}

Hysteresis and impact damping measures were made on 37 wheelchair seating cushions according to ISO 16840-2:2007 Wheelchair seating-Part 2: Determination of physical and mechanical characteristics of devices intended to manage tissue integrity—seat cushions. These measures were then correlated using Spearman and Pearson correlations to investigate the relationship between them. Correlations were also conducted on the subset of cushions comprising only those with planar foam construction. Correlation between the hysteresis measures $\left(\mathrm{h}_{250}\right.$ and $h_{500}$ ) and the mean number of rebounds greater in amplitude than $10 \%$ of the peak acceleration amplitude $\left(\mathrm{R}_{10 \%}\right)$ were weak, as were the correlations between the hysteresis measures and the mean peak first rebound acceleration $\left(\mathrm{a}_{\mathrm{a}}\right)$. Correlations between hysteresis and the mean peak second rebound acceleration $\left(a_{2}\right)$, and also hysteresis and the ratio of first and second peak $\left(a_{2}: a_{a}\right)$

\footnotetext{
${ }^{1}$ * The authors would like to ensure that readers are aware that the term hysteresis, which is used in the ISO 16840 2:2007 version of the standard, may be substituted in future revisions.

${ }^{2}$ Corresponding author
} 
however were moderate. Results demonstrate that the relationship between these two measures is complex. The assertion implicit in ISO 16840-2:2007 is that the two measures are related, but this study shows that these should not be assumed to be equivalent or used interchangeably.

\section{Keywords}

cushion; foam; hysteresis; impact damping; ISO; ISO 16840; ISO 16840-2; mechanical characteristics; standard

\section{Introduction}

Prescription of an appropriate wheelchair seating cushion is a critical factor in the clinical effectiveness of a wheeled mobility solution. "Wheelchair seating cushions must fulfil a variety of requirements in order to meet an individual's specific rehabilitation aims including managing comfort, tissue integrity, postural control, postural alignment and functional enablement." (Hollington et al, 2014) The information available to clinicians when selecting a seating support surface include experience, the theory behind support surfaces, knowledge of material properties, user trials and, if available, interface pressure mapping (IPM) technologies. Unless IPM can be utilised, no scientific data are available for decision making when it comes to comparing the vast range of cushions commercially available.

"The evidence required to facilitate more objective prescription of cushions includes detailed information about the intended user's diagnosis, associated physical and cognitive complications, other aspects of their health, postural presentation, ability, lifestyle, environment, and rehabilitation goals." (Hollington et al, 2014). However there is also a need for scientific data about the performance of seating support surfaces in order that objective comparisons can be made. Ideally, this information, which is specific to each cushion, would take the form of mechanical performance data which can be interpreted clinically in the best interests of the wheelchair user. 
The development of testing methods that can yield these data has been pursued for more than four decades (Cochran et al, 1973, Cochran et al., 1980, Bar, 1991, Nicholson et al., 2003) along with attempts to normalise a uniform terminology to describe wheelchair cushion characteristics (Sprigle et al, 2001) (Waugh et al, 2012). The publication in 2007 of the ISO 16840-2:2007 standard: Wheelchair seating - part 2: Determination of physical and mechanical characteristics of devices intended to manage tissue integrity - Seat cushions (ISO, 2007), was therefore a major step in the development of a standard set of measurements for wheelchair seating support surfaces. These mechanical performance measurements could have the potential to produce globally transferable data enabling objective comparisons of cushions whilst, at the same time, ensuring that manufacturers' claims can be substantiated by data.

ISO 16840-2:2007 defines a set of test procedures for obtaining measures which describe the performance characteristics of wheelchair seating cushions under specific controlled conditions. Each measure is intended to be relevant to the management of tissue integrity, and is accompanied by a rationale linking the test to the clinically relevant properties of the cushions. The standard does however state that "The link to clinical efficacy, although implied has not been validated." and then goes onto express the intention that "this part of ISO 16840 will evolve when evidence of clinical relevance is confirmed." (ISO, 2007). However, "The emergence of this evidence is unlikely unless the standard and its resulting data are familiar to, and better understood by, clinicians." (Hollington et al, 2014)

The aim of this study is to examine the relationship between two of the tests defined in the standard. The first test, load deflection and hysteresis* from section 9 of the standard, describes the compression and recovery characteristics of the cushion as it is subjected to various loads for a duration of $120 \mathrm{~s}$. The second test is the impact damping test from 
section 11 of the standard, and takes a different approach to measuring the response of the cushion under loading conditions on a much shorter time scale. The standard assumes a relationship between these measures: in the rationale to the load deflection and hysteresis test it states "Hysteresis is related to impact damping" and in the rationale to the impact damping test it states "Impact damping is related to hysteresis". It is also further stated in the standard that "Cushions with larger hysteresis values will tend to absorb energy when used on rough surfaces or when dropping down steps, rather than transfer the impact energy to the user's tissues" (ISO, 2007) which implies the relevance of the hysteresis measure to the impact response of the cushion. Sprigle et al. (2010) also agree with this statement stating that, "Ratios of subsequent impacts or rebounds offer an estimate of the damping coefficient of a cushion, and, as stated in the ISO document, reflect aspects of hysteresis." (Sprigle, 2010) It is indeed true that damping and hysteresis are related as the absorption of energy (i.e. hysteresis) results in the damping of rebounds in an impact test. However, Hollington et al. suggest in their paper examining the load deflection and hysteresis measurements that although hysteresis and impact damping are related, impact damping properties of cushions cannot be inferred from hysteresis test results. This is because "cushions with a slower recovery time may recover in the hysteresis testing because 120s is required between measurements, whereas recovery time in impact damping tests is dependent on the rebound reaction after impact." (Hollington et al, 2014) A comparison between ISO16840-2 hysteresis and impact damping tests would help inform this statement and the rationale.

Reports on the ISO16840-2 impact damping test have shown the test to have a "high level of repeatability across different cushions, days and operators." (Sprigle, 2010) However, the reports also highlight that a few issues need to be addressed in the ISO standard test methodology in order to ensure this repeatability. Additionally, certain additional data 
should be reported for improved interpretation of the test (Sprigle, 2010) (Chung, 2009). The ISO16840-2:2007 hysteresis test has also been demonstrated to be a repeatable test method which achieves its objective of differentiating wheelchair cushion performance (Hollington et al, 2014). However, it has also been highlighted that this test must be carefully considered in order to avoid misinterpretation of results in relation to the rationale linked to them. It should be noted that a revision of this standard is currently under preparation and will hopefully address these issues. Nonetheless it is also important that the ISO16840-2:2007 test rationale are explored and tested if clinicians are able to be guided by the data produced.

The specific aim of this study is therefore to test whether there is a correlation between the ISO16840-2:2007 hysteresis and impact damping measures. It is also hoped that this study will enable individuals who wish to interpret these data to make better informed decisions about the conditions under which each measure may be relevant.

\section{Method}

\section{Impact damping}

Impact damping measurements were made on 37 wheelchair seating cushions according to ISO 16840-2:2007. This involved preconditioning, as required by section 7 of the standard, and the impact damping tests as defined in section 11. The following summarises the impact damping test, but for the definitive description of all test procedures and apparatus, please refer to 16840-2:2007.

The test requires an impact damping rigid cushion loading indenter (IDRCLI) which comprises a rigid representation of the inferior surface of the human buttocks and thighs 
when seated. The IDRCLI is loaded such that it will develop a force under gravity of $500 \mathrm{~N}$ $\pm 10 \mathrm{~N}$ (498N in this study), and an accelerometer is mounted on the mid-line of the flat top surface of the IDRCLI at a distance of $127 \mathrm{~mm} \pm 25 \mathrm{~mm}$ from the rear edge $(126 \mathrm{~mm}$ in this study), oriented to measure acceleration normal to the top surface.

To conduct the test a rigid plate is used which is hinged at its front edge such that it rests horizontally, but can be rotated such that its surface can form an angle of at least $10^{\circ}$ to the horizontal. Two $25 \mathrm{~mm} \pm 5 \mathrm{~mm}$ diameter rubber stops ( $25 \mathrm{~mm}$ in this study), with Shore A hardness of 60 , are fixed to the underside front edge corners with centres at $25 \mathrm{~mm}$ from the front and lateral edges, and support the plate when it is horizontal. The cushion is placed on the rigid plate such that its rear edge is aligned with the rear edge of the rigid plate and the IDRCLI is placed on the cushion in the position and alignment intended by the manufacturer. The rigid plate is then raised using a prop such that it is at $10^{\circ}$ to the horizontal. The prop is then removed in less than $0.1 \mathrm{~s}$, and the plate, with cushion and IDRCLI, are allowed to fall back to horizontal.

The test is repeated three times and yields four measures which indicate the magnitude of peak rebound accelerations measured during the test $\left(\mathrm{a}_{\mathrm{a}}\right.$ and $\left.\mathrm{a}_{2}\right)$ and the degree to which these accelerations are damped $\left(R_{10 \%}\right.$ and $\left.a_{2}: a_{a}\right) . a_{a}$ is the mean of the peak of the highest rebound acceleration relative to the baseline; $a_{2}$ is the mean of the peak values of the second highest rebound acceleration relative to the baseline; $a_{2}: a_{a}$ is the ratio of $a_{2}$ to $a_{a}$ reported as a percentage and $\mathrm{R}_{10 \%}$ is the mean number of rebounds with acceleration amplitude greater than $10 \%$ of the peak acceleration. Although not required by the ISO 16840-2:2007 standard, the magnitude of the impact accelerations (first $\left(\mathrm{I}_{\mathrm{a}}\right)$ and second ( $\left.I_{2}\right)$ impacts) were also recorded, and their ratio $\left(I_{2}: I_{a}\right)$ calculated as a percentage (figure 1$)$. 
The cushions tested are listed in table 1 . The cushions were chosen to represent a variety of manufacturers' designs in current clinical use and a range of foam types commonly used in wheelchair seating systems. Cushions were $410 \mathrm{~mm}$ wide by $460 \mathrm{~mm}$ long where available, which was the size judged to be most appropriate to fit the size of the IDRCLI. Where this size was not available commercially, the closest available size was used.

\section{Resilience}

The cushions were also trialled according to the test designated in the ISO16840-2:2007 standard as 'load deflection and hysteresis'. Please refer to this standard for the definitive description of this test. This test requires that each cushion is loaded with a rigid cushion loading indenter (RCLI) which has an inferior surface identical in shape and size to the IDRCLI. The thickness of the cushion is measured at the base points of the RCLI, corresponding to the location of the ischial tuberosities on the cushion and measurements are taken at $8 \mathrm{~N}, 250 \mathrm{~N}, 500 \mathrm{~N}$ and $750 \mathrm{~N}$ as the load is increased, and also at $500 \mathrm{~N}, 250 \mathrm{~N}$ and $8 \mathrm{~N}$ as the load is decreased. The cushion is allowed to equilibrate at each load for $120 \mathrm{~s} \pm 10$ s before each measurement is taken, and the load must be adjusted to the next load required in the cycle within 10s. An Instron 5567 mechanical testing machine (Instron, High Wycombe, United Kingdom) was used to apply these controlled loads and data were collected with Instron Merlin software. As for the impact damping test, the test is repeated three times for each cushion.

The following values at 250N $\left(h_{250}\right)$ and $500 \mathrm{~N}\left(h_{500}\right)$ were computed for each cushion according to the following equations which are given in the standard. 


$$
h_{55}=\frac{\bar{h}_{250}}{\bar{h}_{250}}
$$

Equation 1 $h_{300}=\frac{\bar{h}_{300}}{\bar{h}_{300}}$

Equation 2

where $\bar{h}_{250 c}$ is the average of the three cushion thickness measures at $250 \mathrm{~N}$ during the loading phase, $\bar{h}_{250 u}$ is the average at $250 \mathrm{~N}$ during the unloading phase; and $\bar{h}_{500 \mathrm{c}}$ and $\bar{h}_{500 u}$ are the corresponding averages at $500 \mathrm{~N}$. It should be noted that, although described as hysteresis in the standard, the data yielded by this test is not true hysteresis, but is an indication of the resilience of the cushion under step-wise loading and unloading conditions.

The temperature of the test environment for all tests conformed to the requirements of section 6 of the standard $\left(23^{\circ} \mathrm{C} \pm 2^{\circ} \mathrm{C}\right)$. However it was not possible to guarantee the test environment fully conformed to the humidity requirements of section 6 which requires a relative humidity of $50 \% \pm 5 \%$.

The Pearson and Spearman correlation coefficients were then computed between each of the four impact damping measurements and the two hysteresis measurements. This was done for all cushions, and for the subset of 17 cushions with planar foam and single layer construction (table 1). Statistical significance was set at $p<0.05$ with a Bonferroni correction of 32 to account for the large number of correlations conducted, giving a significance level for each test of $p<0.0015$. The Pearson correlation coefficient was used to investigate the possibility of linear relationships between the hysteresis and impact damping measures, and the Spearman correlation coefficient was used to investigate nonlinear relationships. 


\section{Results}

Impact damping and $\mathrm{h}_{250}$ and $\mathrm{h}_{500}$ measures for each cushion are given in table 2 .

Pearson correlations between impact damping measures and $h_{250} / h_{500}$ measures are given in table 3. The magnitudes of these correlations were varied, with the weakest correlation of -0.074 being observed between the mean peak first rebound acceleration $\left(a_{a}\right)$ and $h_{500}$ for the planar foam cushions; and the strongest of -0.840 being observed between the ratio of first and second peak $\left(\mathrm{a}_{2}: \mathrm{a}_{\mathrm{a}}\right) \mathrm{andh}_{250}$, also for the planar foam cushions. The correlations involving mean peak second rebound acceleration $\left(\mathrm{a}_{2}\right)$ and the ratio of the first and second mean peak accelerations $\left(\mathrm{a}_{2}: \mathrm{a}_{\mathrm{a}}\right)$ tended to be stronger that those involving the mean peak first rebound acceleration $\left(a_{a}\right)$ and the mean number of rebounds greater in amplitude than $10 \%$ of the peak impact amplitude $\left(R_{10 \%}\right)$.

Corresponding Spearman correlations are given in table 4. These showed a similar pattern and grouping to the Pearson correlations, with the weakest correlation of 0.150 being observed between the mean peak first rebound acceleration $\left(a_{a}\right)$ and $h_{250}$ for the planar foam cushions, and strongest correlation of -0.802 being observed between the ratio of first and second peak $\left(a_{2}: a_{a}\right)$ and $h_{250}$, once again for the planar foam cushions.

The averaged impact damping accelerations, $\mathrm{a}_{\mathrm{a}}$ and $\mathrm{a}_{2}$, and ratio $\mathrm{a}_{2}: \mathrm{a}_{\mathrm{a}}$ are presented in Table 6 (supplementary).

\section{Discussion}

In its introduction the ISO 16840-2:2007 standard states that the tests it describes are "not appropriate for ... directly matching these characteristics with the requirements of 
individual users." However in the next sentence it states, "The link to clinical efficacy, although implied, has not been validated." If such validation is to be achieved however, it is important that the meaning of each measure is correctly understood. The results of this study contribute to that understanding by showing that the correlation between the resilience measures $\left(h_{250}\right.$ and $\left.h_{500}\right)$ and impact damping, as defined in ISO 16840-2:2007, is weak to moderate. This is of interest because the standard tells us that these measures and impact damping are related (section 9.1, paragraph 2), but the results from this study show that this relationship cannot be assumed to be an equivalence.

It is perhaps not surprising however that these measurements are not strongly correlated because, although they both consider time dependent properties of the cushions, the time scales over which they are relevant are very different. The thickness measures used in the computation of $h_{250}$ and $h_{500}$, for example, are taken after each load has been applied for $120 \mathrm{~s} \pm 10 \mathrm{~s}$, whereas the impact damping measures examine changing accelerations after an impact, which is typically completed in around one second. This constitutes a difference of approximately two orders of magnitude.

The separate analysis of the planar foam cushion group was motivated by our expectation that the cushions with simpler construction might demonstrate greater within group consistency under both the load deflection and impact damping test conditions. Results showed that correlations within this subset were a little stronger particularly those involving $\mathrm{a}_{2}$ and $\mathrm{a}_{2}: \mathrm{a}_{\mathrm{a}}$. This is an interesting result which may suggest that any relationships between hysteresis and impact damping tests are mildly affected by cushion design. Further study is needed however to investigate the differing influences of cushion architecture and materials choice on the ISO standard measures. 
It is also interesting to compare our findings with those of Ferguson-Pell et al (2015) who used the impact damping parameters, along with other potential indicators of impact damping performance, as the input to a cluster analysis to determine whether these measures could differentiate a sample of 35 wheelchair cushions. Of the ISO 168402:2007 impact damping measures used, Ferguson-Pell et al (2015) found that the mean peak second rebound acceleration $\left(\mathrm{a}_{2}\right)$ or the ratio of the first and second rebound accelerations $\left(a_{a}: a_{2}\right)$ were the strongest predictors of cluster membership. These were the same measures we found to be most strongly correlated with $h_{250}$ and $h_{500}$. This may suggest that $\mathrm{a}_{2}$ and $\mathrm{a}_{2}: \mathrm{a}_{\mathrm{a}}$ may be the impact damping measures offering the best sensitivity and/or specificity when classifying or differentiating cushions.

This difference in the time scales for the two tests is consistent with, and may explain, some of the clinical examples provided in the standard's rationales. When discussing impact damping, for example, the standard links this measurement to the cushion's ability to absorb impact vibration, such as may be experienced when rolling off a kerb: an event with a similar time scale to the impact damping test itself. Similarly, the rationale to the $h_{250}$ and $h_{500}$ test suggests that this measure is linked to the cushion's potential to facilitate a user returning to an upright posture after a lean to the side, an event which may be expected to take place over a comparable time scale to that of the test. Later in the hysteresis rationale however, the standard says "Cushions with larger hysteresis values will tend to absorb energy when used on rough surfaces or when dropping down steps, rather than transfer the impact energy to the user's tissues." This assertion cannot be justified on the basis of time scale, and given its similarity to the impact damping rationale, could be taken to imply a greater correlation between these measures than our results have demonstrated. 
In addition to the difference in time scale considerations, other aspects of the impact damping measures have been identified which may be relevant to our results. In particular, Sprigle et al. (2010) have observed that the rebound accelerations, $a_{a}$ and $a_{2}$ occur when there is limited contact between the IDRCLI and the cushion, and state that "Under this condition the measured acceleration is not reflective of the cushion at all." These authors also cite Chung (2009) who found non-linear responses in the rebound accelerations of three cushions tested according to ISO 16840-2:2007. This implies that, because the harmonic system is not simply damped, the rebound ratio measure is not equal to the ratio of impact peaks (figure 2), and so does not provide reliable information about the actual damping of impacts. In this study we also considered correlations between impact accelerations $\left(l_{a}\right.$ and $\left.I_{2}\right)$ and $h_{250}$ and $h_{500}$ and these yielded spread values (see table 6 in Supplementary Data). The correlations of impact accelerations to $h_{250}$ and $h_{500}$ for the 37 cushion set in this study were weaker than when rebound acceleration was used for the correlation (table 3 and 4). This result comes to support statements offered by other authors (Sprigle, 2010) (Chung, 2009) confirming the complex nature of the cushion response and the need for a multi-factorial output from the cushion testing in order to fully characterise the performance of wheelchair cushions. Indeed, it is interesting to note that the ISO standard focuses on damping alone, but our study also shows that initial impact may also be a clinically relevant measure when trying to establish the effect of a cushion in protecting a user from the initial impact, for example, after dropping off a kerb. These observations are also relevant to the potential for the impact damping measures to inform clinical decision making in tissue damage management.

It is also interesting to compare measurements between laboratories. Both this study and that by Sprigle et al (2010) tested four different types of cushion design, although the high profile Roho single valve cushion is the only cushion common to both studies. The other 
three cushions tested by Sprigle et al (2010) were therefore matched with the closest type in our study for comparison and the results are shown in table 5. For the high profile Roho single valve the $a_{a}$ and $a_{2}$ values were comparable between labs which is reassuring given that the characteristics of this cushion are likely to be highly dependent on its degree of inflation which is user settable.

Although only four of the cushions in our study required user set-up, it is unlikely to be an important factor in explaining our results, it is nonetheless useful to those hoping to interpret the ISO measurements to be aware that the impact damping measure may be highly dependent on set-up, and the test lab conditions may not correspond to the clinical situation. This is perhaps especially the case with more complex cushions such as the Roho Quadtro, which facilitates different levels of inflation in the four quadrants of the cushion.

With regard to comparison with the other cushions tested by Sprigle et al. (2010), results were comparable between the simpler flat foam and visco foam cushions, but not between the cushions with viscous fluid overlays. For these cushions differences are to be expected, and it is impossible to discount differences between the fluid sac overlays as a significant factor in the greater discrepancy seen with the viscous fluid overlay cushions, as well as the setting up of those, which may include a rearrangement post preconditioning step. This procedure remains unclear as it is not listed in the standard.

Positioning of the accelerometer in relation to the hinge may also explain the greater discrepancy observed between studies for the cushions which were not of simple flat design. In this study cushions were positioned with the back edge aligned with the back edge of the hinged plate. The IDRCLI was positioned on the flat cushions as directed in 
the standard with the accelerometer on the mid-plane at $126 \mathrm{~mm}$ from the back edge of the IDRCLI for flat cushions. For contoured cushions however positioning was as intended by the manufacturer, which is also in accordance with the requirements of the standard. For flat cushions therefore, the distance from the accelerometer to the hinge was consistent across all measurements, but for the contoured cushions this could not be guaranteed. It is a limitation of this study that the hinge-to-accelerometer distance was not controlled and further supports the recommendation of Sprigle et al (2010) that the ISO test method provides "an explicit distance from an accelerometer to the axis of rotation."

Finally, it should also be noted that the standard's use of the term hysteresis is not rigorous in that the results of the test characterise the behaviour of the cushion under step-wise loading and unloading, rather than being a measure of true hysteresis. The authors understand that the standard will use the term Resilience in future revisions, and this is more appropriate, being a term which better evokes how readily the cushion restores its original shape when unloaded. We anticipate that this change will facilitate a more intuitive understanding of the measures $h_{250}$ and $h_{500}$ amongst clinicians, especially amongst those without a more technically oriented background, and will assist them in interpreting these measures. We also believe that the clinical illustrations given in the standard relating to a wheelchair user leaning to the side to perform a task, and when using a wheelchair on rough surfaces or when dropping down steps are also more easily understood from the perspective of resilience. This is important because without the engagement of the wider community of wheelchair and seating practitioners the "link to clinical efficacy", which the standard says it implies but has not validated, will be unlikely to emerge. It is also, of course, desirable that established terms such as hysteresis are not redefined, especially in authoritative documents such as ISO standards. 


\section{Conclusion}

ISO 16840-2:2007 tells us that the $h_{250}$ and $h_{500}$ and impact damping measures it defines are related, but the results from this study show this relationship does not take the form of a strong correlation. This means that these measures are not equivalent and interpretation of these measures must consider how the testing conditions compare to the circumstances for which information is sought. Furthermore, the authors concur with the recommendations of Sprigle et al (2010) and Chung (2009) regarding placement of the accelerometer and IDRCLI because the distance between accelerometer and axis of rotation contributes to results variation; and the complexity of the dampening performance, which is not a simple damped harmonic oscillation. Standardized placement of the accelerometer in relation to the impact damping rig is therefore required. The level of confidence in a set of results (namely, the mean peak second rebound acceleration $\left(\mathrm{a}_{2}\right)$ or the ratio of the first and second rebound accelerations $\left(a_{a}: a_{2}\right)$, i.e. impact damping characteristics) from this study are nonetheless in agreement with an equivalent set in those reported in Ferguson-Pell et al (2015). Additionally, it is worth highlighting that all test results may be affected by set-up for those cushions designed to be adjusted to meet the requirements of the user.

\section{Acknowledgements}

The authors wish to thank the South-east Mobility and Rehabilitation Technology Centre in Edinburgh for the loan of equipment and use of their facilities. CTS wishes to thank Mr Adam Dale for support while running the impact damping tests. NC was supervised by CTS as part of his undergraduate studies. 


\section{Declaration}

Competing interests: None declared

Funding: None

Ethical approval: Not required 


\section{References}

Bar CA, (1991) Evaluation of cushions using dynamic pressure measurement, Prosthetics and Orthotics International, 15, 232-240.

Chung, B M. (2009) Dynamic Response of Wheelchair Cushions to the ISO impact damping Test. In Proceeding of the 25th Southern Biomedical Engineering Conference, Miami, FL. New York: Springer

Cochran G van B, Slater G. (1973) Experimental Evaluation of Wheelchair cushions: Report of a Pilot Study, Bulletin of Prosthetics Research, 10-19, 29-61.

Cochran G van B, Palmieri V (1980) Development of Test Methods for Evaluation of Wheelchair Cushions, Bulletin of Prosthetics Research, 10-33, 17, 1, 9-30.

Ferguson-Pell, M. Ferguson-Pell, G. Mohammadi, F. Call, E. (2015) Applying IOS 16840-2 Standard to differentiate impact force dissipation characteristics of selection of commercial wheelchair cushions. Journal of Rehabilitation Research and Development, 52, 41-52.

Hollington J, Hillman S J, Torres-Sánchez C, Boeckx J, Crossan N. (2014) ISO 168402:2007 load deflection and hysteresis measurements for a sample of wheelchair seating cushions. Medical Engineering \& Physics, 36, 509-516.

International Organization for Standardization. (2007) BS ISO 16840-2:2007 Wheelchair seating-Part 2: Determination of physical and mechanical characteristics of devices intended to manage tissue integrity—seat cushions. London: British Standards Institute. 
Nicholson G, Bain D, Ferguson-Pell M. Practical experience in using draft ISO (CD 16840-

2) Test methods for wheelchair seating - part 2: Test methods for devices intended to manage tissue in practice. European Pressure Ulcer Advisory Panel. 2003;5: 3,97-98.

Sprigle S, Press L, Davis K. (2001) Development of uniform terminology and procedures to describe wheelchair cushion characteristics, Journal of rehabilitation Research and Development, 38, 4, 449-461.

Sprigle S, Chung B M, Meyer T. (2010) Assessment of the ISO impact damping Test for Wheelchair Cushions. Assistive Technology, 22, 236-244.

Waugh, KG, Crane, B. Measuring wheelchair seated posture and seating supports: standardization of terms and methodologies. In: Proceedings of 28th International Seating Symposium, 2012 March 7-9; Vancouver BC; Vancouver BC: UBC Interprofessional Continuing Education; 2012. 56-57. 
Tables:

\begin{tabular}{|c|c|c|c|}
\hline Cushion & Construction & Propad $^{3}$ & Planar foam, single layer \\
\hline Roho single valve ${ }^{1}$ & Single compartment, cellular air filled & $50 \mathrm{~mm}$ V33 polyether ${ }^{6}$ & Planar foam, single layer \\
\hline Roho Quadtro $^{1}$ & Multi-compartment, cellular air filled & $75 \mathrm{~mm}$ V33 polyether ${ }^{6}$ & Planar foam, single layer \\
\hline Jay $\mathrm{J}^{2}$ & Contoured foam, single layer with viscous fluid overlay & $50 \mathrm{~mm} \mathrm{CM} 60$ & Planar foam, single layer \\
\hline Jay 3 with Roho ${ }^{2}$ & Contoured foam, single layer with cellular air filled insert & $75 \mathrm{~mm}$ CM60 & Planar foam, single layer \\
\hline Jay $\mathrm{Gel}^{2}$ & Contoured, gel and foam dual layer & $50 \mathrm{~mm}$ CM35 & Planar foam, single layer \\
\hline Flo-tech Contour $^{3}$ & Contoured foam, single layer & 75 mm CM35 & Planar foam, single layer \\
\hline Flo-tech Contour Visco ${ }^{3}$ & Contoured visco-foam, single layer & $50 \mathrm{~mm}$ RX39 & Planar foam, single layer \\
\hline Flo-tech Plus ${ }^{3}$ & Contoured foam, single layer with viscous fluid insert & 75 mm RX39 & Planar foam, single layer \\
\hline Flo-tech Solution ${ }^{3}$ & Viscous fluid sacs overlaid on contoured foam & 50 mm Pink viscose ${ }^{4}$ & Planar foam, single layer \\
\hline Flo-tech Lite ${ }^{3}$ & Contoured foam, single layer & $75 \mathrm{~mm}$ Pink viscose ${ }^{4}$ & Planar foam, single layer \\
\hline Flo-tech Lite Visco ${ }^{3}$ & Contoured visco-foam, single layer & $50 \mathrm{~mm}$ Sunmate $^{7}$ soft & Planar foam, single layer \\
\hline
\end{tabular}




\begin{tabular}{|c|c|c|c|}
\hline Qbitus Mercury $100^{4}$ & Contoured foam, dual layered & $75 \mathrm{~mm}$ Sunmate ${ }^{7}$ soft & Planar foam, single layer \\
\hline Qbitus Mercury $200^{4}$ & Contoured foam, dual layered & 50 mm 3lb chip & Planar foam, single layer \\
\hline Qbitus Mercury $300^{4}$ & Contoured foam, dual layered, with gel-foam insert & 75 mm 3lb chip & Planar foam, single layer \\
\hline Qbitus Qbi-gel $^{4}$ & Planar, gel and foam dual layer & $50 \mathrm{~mm} 6 \mathrm{lb}$ chip & Planar foam, single layer \\
\hline Vicair Adjuster $6^{5}$ & Air sacs in multi-compartmental cover & 75 mm 6lb chip & Planar foam, single layer \\
\hline Vicair Adjuster $10^{5}$ & Air sacs in multi-compartmental cover & $25 \mathrm{~mm}$ Pink viscose ${ }^{4}$ on $50 \mathrm{~mm}$ 3lb chip & Planar foam, dual layered \\
\hline Varilite Evolution & Contoured, mixed foam/air adjusted foam composition & $\begin{array}{l}25 \text { mm Sunmate }{ }^{7} \text { soft on } 25 \mathrm{~mm} \text { CM35 on } 25 \\
\mathrm{~mm} \mathrm{CM60}\end{array}$ & Planar foam, triple layered \\
\hline
\end{tabular}

Table 1. Cushions $\left({ }^{1}\right.$ The Roho Group, Belleville, IL, ${ }^{2}$ Sunrise Medical, Boulder, CO, ${ }^{3}$ Invacare, Elyria, OH, ${ }^{4}$ Qbitus, Halifax, United Kingdom, ${ }^{5}$ Vicair, Wormer, The Netherlands, ${ }^{6}$ Vitafoam, Manchester, United Kingdom, ${ }^{7}$ Dynamic Systems Inc., Leicester, NC) 


\begin{tabular}{|c|c|c|c|c|c|c|}
\hline Cushion & $\mathbf{R}_{10 \%}$ & $\begin{array}{c}a_{a} \\
\left(m / s^{2}\right)(S D)\end{array}$ & $\begin{array}{c}a_{2} \\
\left(\mathrm{~m} / \mathrm{s}^{2}\right)(\mathrm{SD})\end{array}$ & $\begin{array}{l}a_{2}: a_{a} \\
(\%)\end{array}$ & $\mathbf{h}_{250}$ & $h_{500}$ \\
\hline Roho single valve & 4.000 & $8.210(0.146)$ & $4.548(0.173)$ & 55.394 & 0.096 & 0.043 \\
\hline Roho Quadtro & 4.000 & $8.415(0.178)$ & $5.477(0.224)$ & 65.090 & 0.090 & 0.046 \\
\hline Jay J2 & 4.000 & $9.223(0.101)$ & $4.784(0.256)$ & 51.868 & 0.071 & 0.047 \\
\hline Jay 3 with Roho & 4.000 & $8.046(0.591)$ & $4.424(0.676)$ & 54.980 & 0.086 & 0.035 \\
\hline Jay Gel & 5.000 & $9.146(0.299)$ & $5.721(0.516)$ & 62.551 & 0.084 & 0.055 \\
\hline Flo-tech Contour & 2.000 & $4.824(0.262)$ & $1.096(0.037)$ & 22.721 & 0.090 & 0.098 \\
\hline Flo-tech Contour Visco & 2.000 & $6.774(0.260)$ & $2.466(0.082)$ & 36.409 & 0.180 & 0.142 \\
\hline Flo-tech Plus & 2.000 & $8.756(0.160)$ & $2.038(0.330)$ & 23.275 & 0.050 & 0.060 \\
\hline Flo-tech Solution & 3.667 & $9.471(0.143)$ & $6.152(1.331)$ & 64.950 & 0.058 & 0.056 \\
\hline Flo-tech Lite & 2.000 & $5.295(0.455)$ & $1.857(0.376)$ & 35.067 & 0.145 & 0.092 \\
\hline Flo-tech Lite Visco & 3.000 & $9.346(0.207)$ & $4.169(0.003)$ & 44.609 & 0.216 & 0.155 \\
\hline Propad & 2.000 & $6.103(0.792)$ & $1.558(0.131)$ & 25.534 & 0.301 & 0.142 \\
\hline Qbitus Mercury 100 & 2.333 & $7.570(0.099)$ & $2.907(0.341)$ & 38.406 & 0.095 & 0.066 \\
\hline Qbitus Mercury 200 & 4.000 & $9.071(0.291)$ & $5.225(0.778)$ & 57.597 & 0.108 & 0.078 \\
\hline Qbitus Mercury 300 & 2.333 & $7.777(0.314)$ & $3.100(0.671)$ & 39.863 & 0.099 & 0.063 \\
\hline Qbitus Qbi-gel & 5.000 & $9.563(0.053)$ & $7.574(0.346)$ & 79.201 & 0.068 & 0.036 \\
\hline Vicair Adjuster 6 & 3.000 & $8.252(0.725)$ & $4.023(0.452)$ & 48.758 & 0.161 & 0.082 \\
\hline Vicair Adjuster 10 & 3.000 & $7.706(0.171)$ & $3.188(0.041)$ & 41.364 & 0.121 & 0.059 \\
\hline Varilite Evolution & 6.000 & $8.729(0.156)$ & $5.304(0.419)$ & 60.764 & 0.274 & 0.223 \\
\hline $50 \mathrm{~mm}$ V33 polyether & 2.000 & $5.659(0.762)$ & $1.905(0.449)$ & 33.663 & 0.371 & 0.168 \\
\hline $75 \mathrm{~mm}$ V33 polyether & 2.000 & $5.836(0.208)$ & $2.161(0.282)$ & 37.029 & 0.253 & 0.121 \\
\hline 50 mm CM60 & 2.000 & $4.367(0.773)$ & $3.037(0.890)$ & 69.531 & 0.091 & 0.087 \\
\hline $75 \mathrm{~mm} \mathrm{CM60}$ & 2.000 & $3.806(0.118)$ & $2.647(0.036)$ & 69.545 & 0.058 & 0.040 \\
\hline $50 \mathrm{~mm} \mathrm{CM35}$ & 2.667 & $8.811(0.325)$ & $3.595(0.764)$ & 40.800 & 0.267 & 0.121 \\
\hline 75 mm CM35 & 2.000 & $6.132(0.069)$ & $2.194(0.052)$ & 35.778 & 0.215 & 0.115 \\
\hline 50 mm RX39 & 2.000 & $7.911(0.252)$ & $3.037(0.296)$ & 38.392 & 0.292 & 0.138 \\
\hline 75 mm RX39 & 2.000 & $5.422(0.394)$ & $2.471(0.453)$ & 45.577 & 0.240 & 0.142 \\
\hline
\end{tabular}




\begin{tabular}{|c|c|c|c|c|c|c|}
\hline $50 \mathrm{~mm}$ Pink viscose & 3.000 & $9.406(0.131)$ & $4.230(0.170)$ & 44.966 & 0.282 & 0.140 \\
\hline $75 \mathrm{~mm}$ Pink viscose & 3.000 & $9.350(0.276)$ & $3.501(0.514)$ & 37.447 & 0.307 & 0.196 \\
\hline $50 \mathrm{~mm}$ Sunmate soft & 3.000 & $9.527(0.088)$ & $5.312(0.060)$ & 55.754 & 0.078 & 0.068 \\
\hline $75 \mathrm{~mm}$ Sunmate soft & 3.000 & $9.414(0.131)$ & $4.210(0.035)$ & 44.722 & 0.066 & 0.058 \\
\hline $50 \mathrm{~mm}$ 3lb chip & 3.667 & $8.099(0.054)$ & $5.162(0.066)$ & 63.732 & 0.099 & 0.069 \\
\hline 75 mm 3lb chip & 3.667 & $7.446(0.360)$ & $4.798(0.163)$ & 64.442 & 0.118 & 0.046 \\
\hline 50 mm 6lb chip & 5.000 & $9.377(0.077)$ & $7.941(0.365)$ & 84.686 & 0.074 & 0.063 \\
\hline 75 mm 6lb chip & 4.333 & $9.124(0.149)$ & $7.148(0.777)$ & 78.344 & 0.041 & 0.027 \\
\hline $25 \mathrm{~mm}$ Pink viscose on $50 \mathrm{~mm}$ 3lb chip & 4.000 & $8.929(0.481)$ & $4.648(0.425)$ & 52.057 & 0.114 & 0.066 \\
\hline $\begin{array}{l}25 \mathrm{~mm} \text { Sunmate soft on } 25 \mathrm{~mm} \mathrm{CM} 35 \text { on } \\
25 \mathrm{~mm} \mathrm{CM} 60\end{array}$ & 2.000 & $4.920(0.037)$ & $1.693(0.147)$ & 34.408 & 0.089 & 0.155 \\
\hline
\end{tabular}

Table 2. Impact damping and hysteresis tests results. All values are the averages of three measurements as required by ISO 16840-2:2007. 


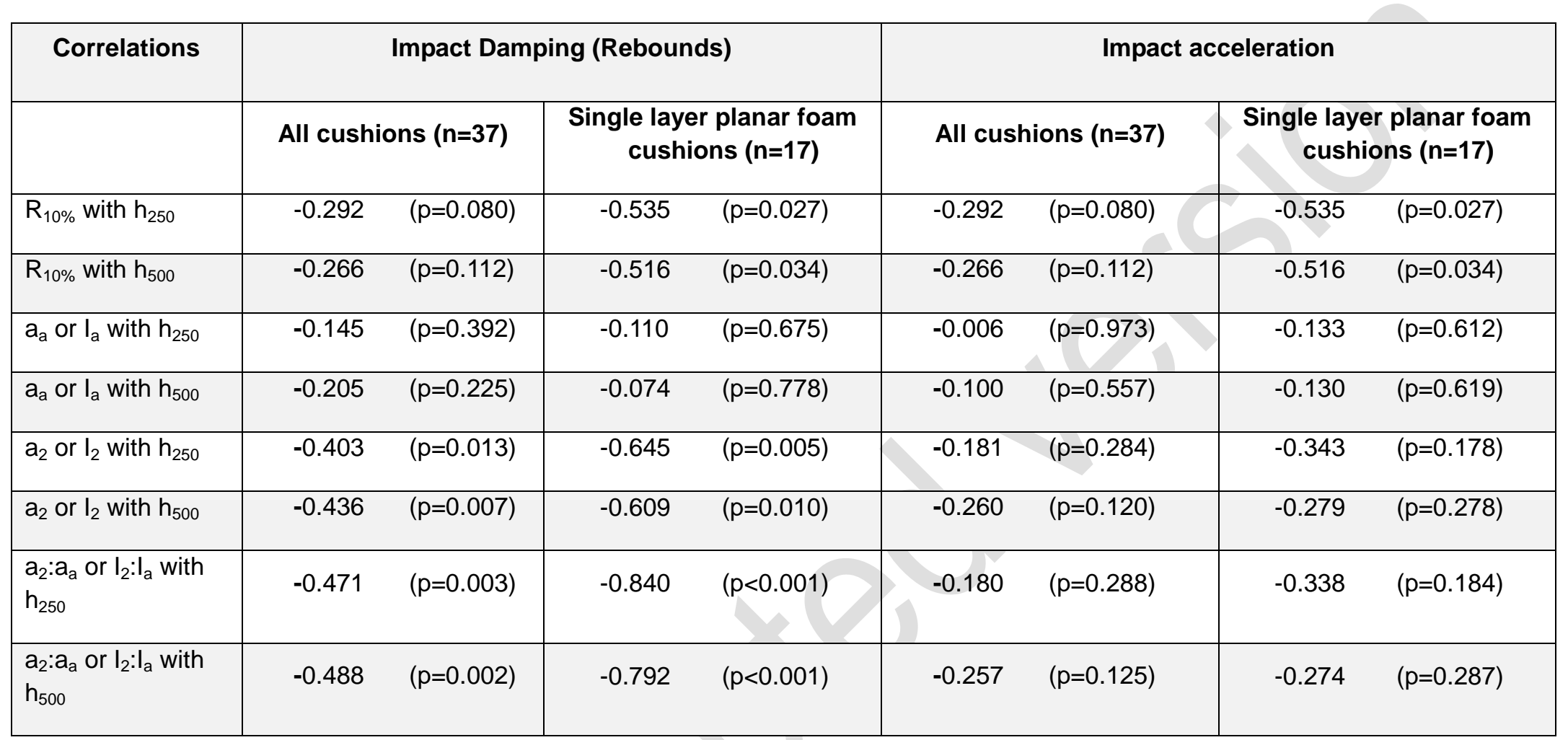

Table 3. Pearson correlation coefficients between ISO 16840-2:2007 impact damping (a) or impact acceleration (I) measures and hysteresis measures. 


\begin{tabular}{|c|c|c|c|c|}
\hline \multirow{3}{*}{$\begin{array}{r}\text { Correlations } \\
\mathrm{R}_{10 \%} \text { with } \mathrm{h}_{250}\end{array}$} & \multicolumn{2}{|c|}{ Impact Damping (Rebounds) } & \multicolumn{2}{|c|}{ Impact acceleration } \\
\hline & All cushions $(n=37)$ & $\begin{array}{l}\text { Single layer planar foam } \\
\text { cushions }(n=17)\end{array}$ & All cushions $(n=37)$ & $\begin{array}{c}\text { Single layer planar foam } \\
\text { cushions }(n=17)\end{array}$ \\
\hline & $-0.334 \quad\left(p=0.043^{*}\right)$ & $\begin{array}{ll}-0.428 \quad\left(p=0.087^{*}\right) \\
\end{array}$ & $-0.334 \quad\left(p=0.043^{\star}\right)$ & $-0.428 \quad\left(p=0.087^{\star}\right)$ \\
\hline $\mathrm{R}_{10 \%}$ with $\mathrm{h}_{500}$ & $-0.505 \quad\left(p=0.001^{*}\right)$ & $\left(p=0.044^{*}\right)$ & $-0.505 \quad\left(p=0.001^{*}\right)$ & $-0.494 \quad\left(p=0.044^{\star}\right)$ \\
\hline$a_{a}$ or $l_{a}$ with $h_{250}$ & $(p=0.103)$ & $(p=0.566)$ & $-0.031 \quad(p=0.858)$ & $-0.142 \quad(p=0.373)$ \\
\hline$a_{a}$ or $l_{a}$ with $h_{500}$ & $-0.269 \quad(p=0.108)$ & $(p=0.515)$ & $-0.079 \quad(p=0.640)$ & $-0.378 \quad(p=0.136)$ \\
\hline $\mathrm{a}_{2}$ or $\mathrm{I}_{2}$ with $\mathrm{h}_{250}$ & $-0.400 \quad(p=0.015)$ & $(p=0.021)$ & $-0.268 \quad(p=0.109)$ & $(p=0.142)$ \\
\hline$a_{2}$ or $I_{2}$ with $h_{500}$ & $(p<0.001)$ & $(p=0.012)$ & $(p=0.024)$ & $(p=0.150)$ \\
\hline $\begin{array}{l}\mathrm{a}_{2}: \mathrm{a}_{\mathrm{a}} \text { or } \mathrm{I}_{2}: \mathrm{l}_{\mathrm{a}} \text { with } \\
\mathrm{h}_{250}\end{array}$ & $(p=0.003)$ & $(p<0.001)$ & $(p=0.110)$ & $(p=0.160)$ \\
\hline $\begin{array}{l}a_{2}: a_{a} \text { or } l_{2}: l_{a} \text { with } \\
h_{500}\end{array}$ & $-0.603 \quad(p<0.001)$ & $(p<0.001)$ & $(p=0.025)$ & $(p=0.164)$ \\
\hline
\end{tabular}

Table 4. Spearman correlation coefficients between ISO 16840-2:2007 impact damping (a) or impact acceleration (I) measures and hysteresis measures. 


\begin{tabular}{|l|l|c|c|}
\hline Cushion & Study & $\begin{array}{c}\text { Initial rebound } \\
\text { acceleration } \\
\mathrm{a}_{\mathrm{a}}\left(\mathrm{ms}^{-2}\right)(\mathrm{SD})\end{array}$ & $\begin{array}{r}2^{\text {nd }} \text { rebound } \\
\text { acceleration } \\
\mathrm{a}_{2}\left(\mathrm{~ms}^{-2}\right)(\mathrm{SD})\end{array}$ \\
\hline $\begin{array}{l}\text { Roho High Profile Single } \\
\text { Valve }\end{array}$ & This study & $8.210(0.146)$ & $4.548(0.173)$ \\
$\begin{array}{l}\text { Roho High Profile Single } \\
\text { Valve }\end{array}$ & Sprigle et al [3] (day 1) & $7.88(0.27)$ & $6.27(0.23)$ \\
\hline Flo-tech Solution & This study & $9.471(0.143)$ & $6.152(1.331)$ \\
\hline Cloud (Otto Bock USA) & Sprigle et al [3] (day 1) & $4.95(0.3)$ & $3.98(0.22)$ \\
\hline Flo-tech Visco Lite & This study & $9.346(0.207)$ & $4.169(0.003)$ \\
Dream (Allegro Medical) & Sprigle et al [3] (day 1) & $10.02(0.44)$ & $5.28(0.22)$ \\
\hline $75 \mathrm{~mm}$ CM60 & This study & $3.806(0.118)$ & $2.647(0.036)$ \\
\hline $\begin{array}{l}75 \mathrm{~mm} \text { (3") flat HR45 } \\
\text { Foam \#1 }\end{array}$ & Sprigle et al [3] (day 1) & $4.73(0.14)$ & $1.72(0.36)$ \\
\hline
\end{tabular}

Table 5. Comparison of initial rebound and second rebound acceleration results from this study and for day 1 of Sprigle et al [3].

Supplementary data:

\begin{tabular}{|l|c|c|c|}
\hline Cushion & $\begin{array}{c}\mathbf{I}_{\mathbf{a}} \\
\left(\mathbf{m} / \mathbf{s}^{2}\right)(\mathbf{S D})\end{array}$ & $\begin{array}{c}\mathbf{I}_{2} \\
\left(\mathbf{m} / \mathbf{s}^{2}\right)(\mathbf{S D})\end{array}$ & $\begin{array}{c}\mathbf{I}_{2}: \mathbf{I}_{\mathbf{a}} \\
(\%)\end{array}$ \\
\hline Roho single valve & $9.191(0.005)$ & $8.071(0.344)$ & 87.818 \\
\hline Roho Quadtro & $9.407(0.078)$ & $8.947(0.209)$ & 95.103 \\
\hline Jay J2 & $9.178(0.022)$ & $8.190(0.099)$ & 89.231 \\
\hline Jay 3 with Roho & $9.350(0.028)$ & $7.927(1.189)$ & 84.784 \\
\hline Jay Gel & $9.178(0.522)$ & $8.757(0.522)$ & 95.409 \\
\hline Flo-tech Contour & $9.192(0.008)$ & $1.078(0.081)$ & 11.724 \\
\hline Flo-tech Contour Visco & $9.200(0.014)$ & $3.549(0.218)$ & 38.578 \\
\hline Flo-tech Plus & $9.198(0.002)$ & $4.140(0.306)$ & 45.006 \\
\hline Flo-tech Solution & $9.184(0.025)$ & $8.882(0.383)$ & 96.705 \\
\hline Flo-tech Lite & $9.184(0.023)$ & $2.163(0.692)$ & 23.552 \\
\hline
\end{tabular}




\begin{tabular}{|c|c|c|c|}
\hline Flo-tech Lite Visco & $9.186(0.006)$ & $7.301(0.954)$ & 79.486 \\
\hline Propad & $9.218(0.010)$ & $2.631(0.249)$ & 28.546 \\
\hline Qbitus Mercury 100 & $9.180(0.014)$ & $4.227(0.086)$ & 46.046 \\
\hline Qbitus Mercury 200 & $9.200(0.002)$ & $7.172(1.147)$ & 77.953 \\
\hline Qbitus Mercury 300 & $9.203(0.011)$ & $5.410(0.549)$ & 58.779 \\
\hline Qbitus Qbi-gel & $9.182(0.047)$ & $9.195(0.011)$ & 100.145 \\
\hline Vicair Adjuster 6 & $9.202(0.021)$ & $7.042(0.816)$ & 76.524 \\
\hline Vicair Adjuster 10 & $9.261(0.016)$ & $5.375(0.064)$ & 58.041 \\
\hline Varilite Evolution & $9.224(0.009)$ & $9.093(0.103)$ & 98.573 \\
\hline $50 \mathrm{~mm}$ V33 polyether & $9.391(0.081)$ & $3.174(0.318)$ & 33.797 \\
\hline $75 \mathrm{~mm}$ V33 polyether & $9.180(0.028)$ & $3.898(0.452)$ & 42.462 \\
\hline $50 \mathrm{~mm}$ CM60 & $9.434(0.071)$ & $3.967(0.734)$ & 42.054 \\
\hline 75 mm CM60 & $9.313(0.052)$ & $3.202(0.132)$ & 34.377 \\
\hline $50 \mathrm{~mm} \mathrm{CM} 35$ & $9.252(0.016)$ & $8.435(0.851)$ & 91.170 \\
\hline 75 mm CM35 & $9.221(0.027)$ & $3.636(0.115)$ & 39.435 \\
\hline 50 mm RX39 & $9.217(0.017)$ & $5.726(0.364)$ & 62.127 \\
\hline 75 mm RX39 & $9.200(0.016)$ & $3.799(0.687)$ & 41.293 \\
\hline $50 \mathrm{~mm}$ Pink viscose & $9.194(0.005)$ & $9.115(0.090)$ & 99.141 \\
\hline $75 \mathrm{~mm}$ Pink viscose & $9.171(0.012)$ & $8.591(0.559)$ & 93.683 \\
\hline $50 \mathrm{~mm}$ Sunmate soft & $9.218(0.002)$ & $9.214(0.002)$ & 99.964 \\
\hline $75 \mathrm{~mm}$ Sunmate soft & $9.226(0.028)$ & $7.895(0.456)$ & 85.577 \\
\hline 50 mm 3lb chip & $9.249(0.024)$ & $8.538(0.475)$ & 92.309 \\
\hline 75 mm 3lb chip & $9.215(0.024)$ & $6.804(0.433)$ & 73.837 \\
\hline 50 mm 6lb chip & $9.225(0.007)$ & $9.225(0.007)$ & 100.000 \\
\hline 75 mm 6lb chip & $9.239(0.011)$ & $9.239(0.011)$ & 100.000 \\
\hline $25 \mathrm{~mm}$ Pink viscose on $50 \mathrm{~mm}$ 3lb chip & $9.207(0.009)$ & $8.917(0.415)$ & 96.850 \\
\hline $\begin{array}{l}25 \mathrm{~mm} \text { Sunmate soft on } 25 \mathrm{~mm} \mathrm{CM} 35 \text { on } \\
25 \mathrm{~mm} \text { CM60 }\end{array}$ & $9.220(0.016)$ & $2.423(0.212)$ & 26.276 \\
\hline
\end{tabular}

Table 6. Impact acceleration tests results. All values are the averages of three measurements as per rebound acceleration recording required by ISO 16840-2:2007. 
Figures:

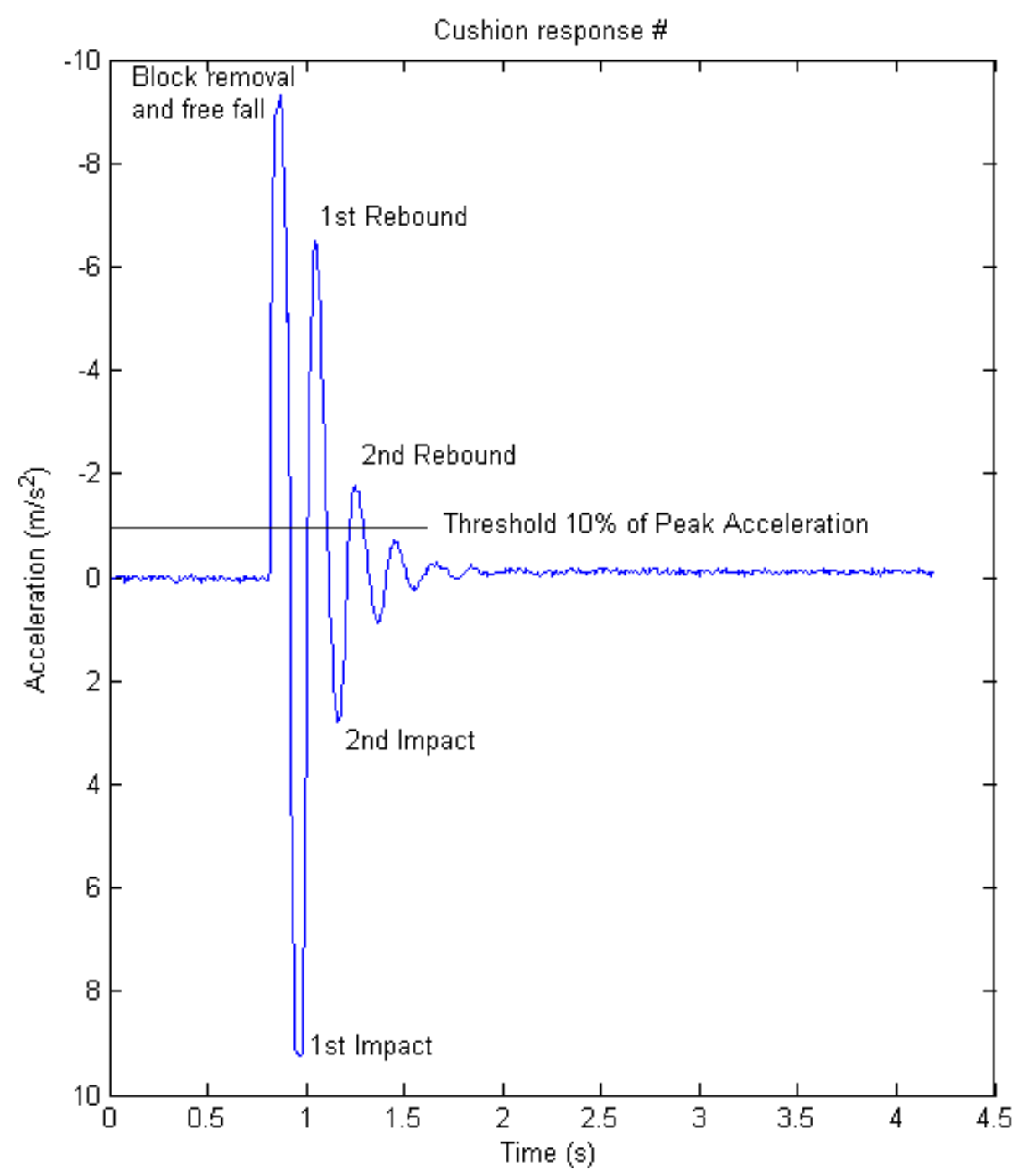

Figure 1: Measures required by the ISO 16840-2:2007 standard
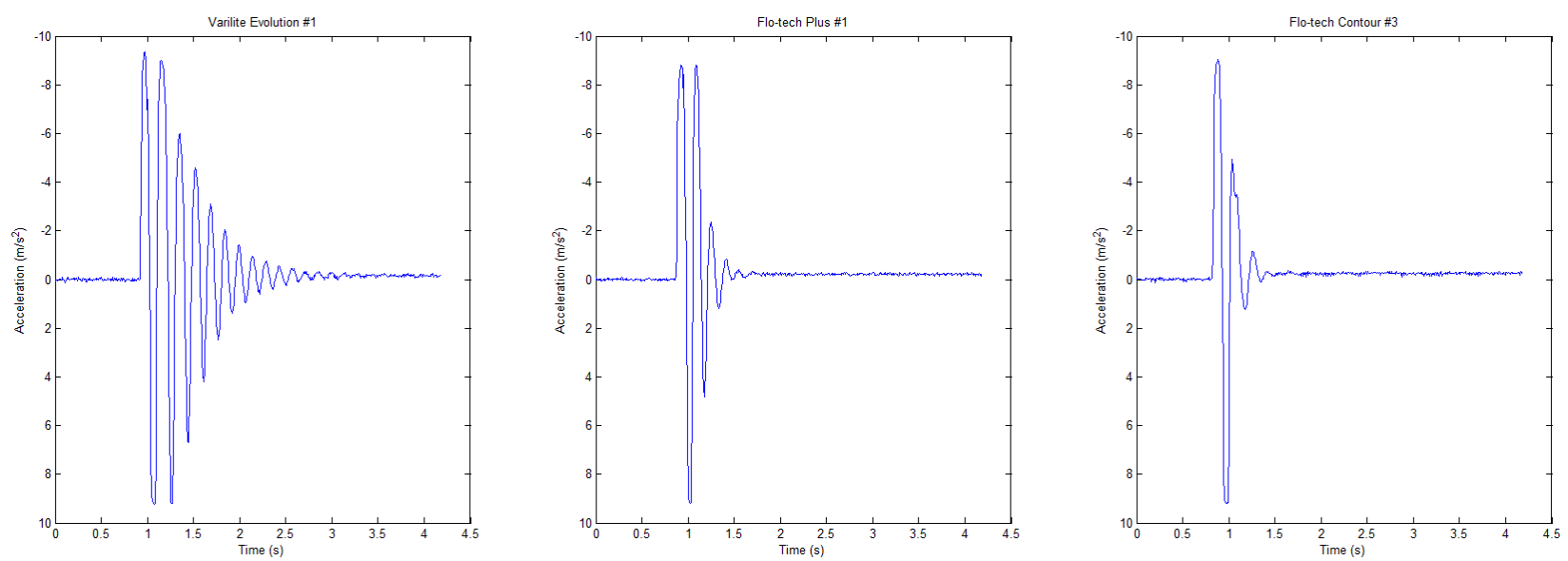

Figure 2: Three examples of impact peaks on cushions with different behaviour 